\title{
EVIDENCE-BASED MIDWIFERY PRACTICE - PRZEGLĄD ŚWIATOWEGO PIŚMIENNICTWA
}

\section{EVIDENCE-BASED MIDWIFERY PRACTICE - REVIEW OF WORLD LITERATURE}

\author{
Jarosława Belowska, Aleksander Zarzeka, Mariusz Panczyk, Joanna Gotlib \\ Zakład Dydaktyki i Efektów Kształcenia \\ Warszawski Uniwersytet Medyczny
}

DOI: http://dx.doi.org/10.20883/pielpol.2016.17

\begin{abstract}
STRESZCZENIE
Zastosowanie evidence-based midwifery practice w wybranych grupach specjalistów nauk o zdrowiu jest tematem szeroko podejmowanym w dostępnej, aktualnej literaturze światowej. Celem pracy była analiza dostępnego, aktualnego piśmiennictwa światowego podejmującego szeroko pojętą problematykę praktyki zawodowej opartej na faktach i dowodach naukowych w grupie położnych.

Wyszukiwanie piśmiennictwa przeprowadzone zostało przez dyplomowanych bibliotekarzy z Biblioteki Głównej Warszawskiego Uniwersytetu Medycznego. Dokonano analizy światowego piśmiennictwa naukowego indeksowanego w bazach: EMBASE, PROQUEST, PUBMED, SCOPUS. Analizowano artykuły w języku angielskim z lat 2000-2013 (data publikacj 1.01.2000-12.11.2013). W dostępnym, światowym piśmiennictwie odnaleziono jedynie 16 pozycji dotyczących grupy zawodowej położnych. Poszerzenie kryteriów wyszukiwania na pozycje piśmiennictwa nieindeksowane w światowych bazach pozwoliło na odnalezienie kolejnych 17 pozycji piśmiennictwa. Prezentowana analiza piśmiennictwa oparta jest na 31 pozycjach piśmiennictwa.

W pracy przeanalizowano szczegółowo m.in.: 1) rodzaje publikacji (przeglądy systematyczne, artykuły oryginalne, studium przypad$\mathrm{ku}, 2)$ tematykę badań podejmowanych w światowym piśmiennictwie, 3) rodzaje czasopism, w których publikowane są prace z obszaru evidence-based midwifery practice (wraz z podaniem współczynnika IF, najbardziej wpływowych autorów i publikacji).
\end{abstract}

SŁOWA KLUCZOWE: praktyka zawodowa, dowody naukowe, literatura, położne.

\section{Wprowadzenie}

Pojęcie i założenia medycyny opartej na danych naukowych (ang. evidence-based medicine - EBM) opracowali epidemiolodzy kliniczni z Uniwersytetu McMastera w Hamilton (Kanada). Określenia tego po raz pierwszy użył w 1991 r. Gordon Guyatt, profesor medycyny i epidemiologii klinicznej, w materiale informacyjnym dla lekarzy. „Rezydentów naucza się postawy »oświeconego sceptycyzmu«, w odniesieniu do stosowanych metod diagnostycznych, terapeutycznych i oceny rokowania w codziennym postępowaniu

\begin{abstract}
The application of evidence-based midwifery practice in selected groups of specialists in health sciences is a subject frequently addressed in the currently available world literature. The aim of this study was to analyze the available, up-to-date world literature on the broadly understood subject of professional practice based on facts and scientific evidence in the group of midwives.

The literature search was conducted by chartered librarians from the Main Library of Medical University of Warsaw. The analysis covered world scientific literature indexed in the following databases: EMBASE, PROQUEST, PUBMED, SCOPUS. It focused on articles in the English language from the years $2000-2013$ (date of publication: 1 January 2000 to 12 November 2013). Only 16 publications concerning the professional group of midwives were found in the available world literature. Other 17 publications were found when the criteria were extended to items not indexed in world databases. The presented analysis of literature is based on 31 publications.

The study provides a detailed analysis of, among others, (1) types of publications (systematic surveys, original articles, case study), (2) research subjects reported in world literature, (3) types of journals in which publications from the area of evidence-based midwifery practice appear (with the IF coefficient of the most influential authors and publications).
\end{abstract}

KEYWORDS: professional practice, scientific evidence, literature, midwives.

z pacjentami. Takie podejście nazywa się evidence-based medicine. (...) Celem jest uświadomienie, na jakich danych naukowych opiera się czyjaś praktyka, na ile te dane są wiarygodne i jakie wnioski można z nich wyciągnąć. Stosowanie tej strategii wymaga jasnego sformułowania odpowiednich pytań, dokładnego przeszukania piśmiennictwa odnoszącego się do określonej sytuacji klinicznej oraz wyważonego zastosowania wyciągniętych wniosków do rozwiązania problemu klinicznego" [1].

Idea evidence-based medicine, mimo że na świecie rozwija się dopiero od kilkunastu lat, to już uzna- 
na została za przełomową ideę w medycynie [2-8]. Do 2000 r. ukazało się około 200 poważnych rozpraw w postaci książkowej i 1500 artykułów oraz działało około 200 witryn internetowych poświęconych EBM [9].

Pojęcie EBM zostało z czasem „zapożyczone przez inne dziedziny kliniczne, takie jak pielęgniarstwo czy położnictwo, i w efekcie można dziś mówić o evidence-based practice (EBP) oraz jego zastosowaniu w wybranych grupach specjalistów nauk o zdrowiu, czyli empirycznej weryfikacji przyjmowanych założeń oraz otrzymywanych wyników" [10].

\section{Cel pracy}

Celem pracy była analiza dostępnego, aktualnego piśmiennictwa światowego, podejmującego szeroko pojętą problematykę praktyki zawodowej położnych opartej na faktach i dowodach naukowych.

\section{Przegląd piśmiennictwa. Kryteria doboru piśmiennictwa}

Wyszukiwanie piśmiennictwa przeprowadzone zostało przez dyplomowanych bibliotekarzy z Biblioteki Głównej Warszawskiego Uniwersytetu Medycznego.

Dokonano analizy światowego piśmiennictwa naukowego indeksowanego w bazach: EMBASE, PROQUEST, PUBMED, SCOPUS. Analizowano artykuły w języku angielskim z lat 2000-2013 (data publikacji 1.01.2000-12.11.2013). Szczegółowe kryteria wyszukiwania - słowa kluczowe oraz deskryptory wykorzystane do wyszukiwania w poszczególnych bazach piśmiennictwa światowego - przedstawiono w tabeli 1.

Tabela 1. Szczegółowe kryteria wyszukiwania piśmiennictwa w wybranych bazach piśmiennictwa światowego

Table 1. Detailed criteria of literature search in selected world literature databases

\begin{tabular}{|c|c|}
\hline $\begin{array}{l}\text { Baza piśmiennictwa/ } \\
\text { Databases }\end{array}$ & $\begin{array}{c}\text { Kryteria wyszukiwania/ } \\
\text { Criteria }\end{array}$ \\
\hline EMBASE & $\begin{array}{c}\text { ‘evidence based nursing': de AND practice:de } \\
\text { AND ([english]/lim OR [polish]/lim) AND [2000- } \\
\text { 2014]/py }\end{array}$ \\
\hline PROQUEST & $\begin{array}{l}\text { su (evidenceBased Nursing) AND su(Health } \\
\text { Knowledge, Attitudes, Practice) }\end{array}$ \\
\hline PUBMED & $\begin{array}{l}\text { (evidence based nursing [MeSH Terms]) AND } \\
\text { Health Knowledge, Attitudes, Practice [MeSH } \\
\text { Terms] („,evidence based practice” [MeSH Ma- } \\
\text { jor Topic]) AND „,health knowledge, attitudes, } \\
\text { practice” [MeSH Major Topic]) AND „dietetics” } \\
\text { [MeSH Major Topic]) OR „physical therapists” } \\
\text { [MeSH Major Topic] }\end{array}$ \\
\hline SCOPUS & $\begin{array}{l}\text { KEY („evidence based nursing”) AND KEY } \\
\text { (knowledge attitudes practice)KEY („evidence } \\
\text { based practice”) AND KEY (nurs*) OR KEY } \\
\text { (diet*) OR KEY (physiotherap*) AND KEY }^{\text {(knowledge attitudes practice) }}\end{array}$ \\
\hline
\end{tabular}

Źródło: opracowanie własne

Source: author's own analysis
W dostępnym, światowym piśmiennictwie odnaleziono jedynie 16 pozycji dotyczących grupy zawodowej położnych; 3 spośród tych pozycji odnalezione zostały w więcej niż jednej bazie. Poszerzenie kryteriów wyszukiwania na pozycje piśmiennictwa nieindeksowane w światowych bazach pozwoliło na odnalezienie kolejnych 17 pozycji piśmiennictwa. Prezentowana analiza piśmiennictwa oparta jest na 31 pozycjach piśmiennictwa.

Przeglądu piśmiennictwa dokonano według trzech kryteriów:

- $\quad$ przegląd piśmiennictwa według rodzajów publikowanych artykułów,

- $\quad$ przegląd piśmiennictwa według podejmowanej tematyki,

- $\quad$ przegląd piśmiennictwa według rodzajów czasopism.

\section{Przegląd piśmiennictwa według rodzajów publikowanych artykułów}

Blisko 97\% spośród odnalezionych prac, zarówno indeksowanych, jak i nieindeksowanych, stanowiły artykuły oryginalne, a jedynie 1 pozycja była w formie editorialu. Ponadto odszukane zostały 2 pozycje książkowe, które ze względu na poprawność merytoryczną przeprowadzania przeglądu piśmiennictwa naukowego zostały wyłączone z dalszej analizy. Najwięcej artykułów dotyczących wykorzystywania badań naukowych w położnictwie zostało odnalezionych w internetowej bazie danych PUBMED. Szczegółowe wyniki analizy przedstawiono w tabeli 2.

Tabela 2. Przegląd piśmiennictwa według rodzajów publikowanych artykułów

Table 2. Survey of literature according to types of articles published

\begin{tabular}{ccccc}
\hline $\begin{array}{c}\text { Baza } \\
\text { piśmiennictwa/ } \\
\text { Database }\end{array}$ & $\begin{array}{c}\text { Przegląd } \\
\text { systematyczny/ } \\
\text { Systemic } \\
\text { review }\end{array}$ & $\begin{array}{c}\text { Artykuł } \\
\text { oryginalny/ } \\
\text { Original } \\
\text { article }\end{array}$ & $\begin{array}{c}\text { Studium } \\
\text { przypadku/ } \\
\text { Case report }\end{array}$ & $\begin{array}{c}\text { Edytorial/ } \\
\text { Editorial }\end{array}$ \\
\hline EMBASE & 0 & 0 & 0 & 0 \\
PROQUEST & 0 & 1 & 0 & 0 \\
PUBMED & 0 & 10 & 0 & 0 \\
SCOPUS & 0 & 2 & 0 & 0 \\
$\begin{array}{c}\text { Pozycje } \\
\text { nieindeksowane }\end{array}$ & 0 & 17 & 0 & 1 \\
\hline
\end{tabular}

Źródło: opracowanie własne

Source: author's own analysis

\section{Przegląd piśmiennictwa według podejmowanej tematyki}

Kolejnym kryterium przyjętym w badaniach była analiza dostępnego piśmiennictwa według podejmowanej tematyki. Najwięcej publikacji dotyczyło położnictwa (77,4\% wszystkich analizowanych publikacji). Jedynie 
4 odnalezione pozycje dotyczyły zagadnień związanych z pielęgniarstwem (12,9\%). Zdecydowanie najmniejsza liczba publikacji dotyczyła szeroko pojętych nauk o zdrowiu: tylko 3,2\% artykułów. Szczegółowe wyniki analizy przedstawiono w tabeli 3.

Tabela 3. Przegląd światowego piśmiennictwa według podejmowanej tematyki

Table 3. Survey of world literature according to subjects

\begin{tabular}{ccc}
\hline Dziedzina/Domain & $\begin{array}{c}\text { Liczba publikacji/ } \\
\text { Number of publica- } \\
\text { tions }\end{array}$ & Procent/Percent \\
\hline MIDWIFERY & 24 & $77,4 \%$ \\
NURSING & 4 & $12,9 \%$ \\
HEALTH CARE SCIEN- & 1 & $3,2 \%$ \\
CES \& SERVICES & 1 & \\
\hline
\end{tabular}

Źródło: opracowanie własne

Source: author's own analysis

\section{Przegląd piśmiennictwa według czasopism - analiza bibliometryczna}

Do analizy cytowań wykorzystano dane zebrane z baz bibliograficzno-abstraktowych: GOOGLE SCHOLAR, SCOPUS oraz WEB OF SCIENCE. Wartości współczynnika impact factor zostały zebrane na podstawie bazy JOURNAL CITATION REPORTS $®$ (Thomson Reuters), a h-index (indeks Hirscha) na podstawie danych bazy SCOPUS.

Analizowano dostępne piśmiennictwo według tytułów czasopism i największej liczby publikacji (Tabela 4), według najbardziej wpływowych publikacji ocenionych liczbą cytowań oraz wskaźnikiem impact factor (Tabela 5).

Czasopisma, w których najczęściej publikowane są artykuły związane z praktyką zawodową położnych opartą na badaniach naukowych, to "Journal of Midwifery and Women's Heath", „The Practising Midwife” oraz „Midwifery” (Tabela 4).

Tabela 4. Analiza piśmiennictwa według tytułów czasopism o największej liczbie publikacji

Table 4. Analysis of literature according to titles of journals with the largest number of publications

\begin{tabular}{cccc}
\hline $\begin{array}{c}\text { Czasopismo/ } \\
\text { Journal) }\end{array}$ & $\begin{array}{c}\text { Dziedzina/ } \\
\text { Domain }\end{array}$ & $\begin{array}{c}\text { Liczba publikacji/ } \\
\text { Number } \\
\text { of publications }\end{array}$ & $\begin{array}{c}\text { Procent/ } \\
\text { Percent }\end{array}$ \\
\hline $\begin{array}{c}\text { Journal of Midwifery } \\
\text { and Women's Health }\end{array}$ & MIDWIFERY & 12 & $38,7 \%$ \\
$\begin{array}{c}\text { The Practising } \\
\text { Midwife }\end{array}$ & MIDWIFERY & 8 & $25,8 \%$ \\
\hline $\begin{array}{c}\text { Midwifery } \\
\text { Social Science } \\
\text { and Medicine }\end{array}$ & $\begin{array}{c}\text { MEALTHFERY } \\
\text { SCIENCES }\end{array}$ & 2 & $6,45 \%$ \\
\hline
\end{tabular}

\begin{tabular}{|c|c|c|c|}
\hline $\begin{array}{l}\text { Nurse Education } \\
\text { in Practice }\end{array}$ & NURSING & 1 & $3,2 \%$ \\
\hline $\begin{array}{l}\text { Journal of Clinical } \\
\text { Nursing }\end{array}$ & NURSING & 1 & $3,2 \%$ \\
\hline $\begin{array}{l}\text { British Journal } \\
\text { of Midwifery }\end{array}$ & MIDWIFERY & 1 & $3,2 \%$ \\
\hline $\begin{array}{l}\text { Journal of Nursing } \\
\text { Scholarship }\end{array}$ & NURSING & 1 & $3,2 \%$ \\
\hline $\begin{array}{c}\text { Journal of Advanced } \\
\text { Nursing }\end{array}$ & NURSING & 1 & $3,2 \%$ \\
\hline $\begin{array}{l}\text { Evidence Based } \\
\text { Midwifery }\end{array}$ & MIDWIFERY & 1 & $3,2 \%$ \\
\hline
\end{tabular}

Źródło: opracowanie własne

Source: author's own analysis

Tabela 5. Analiza piśmiennictwa według najbardziej wpływowych publikacji

Table 5. Analysis of literature according to the most influential publications

\begin{tabular}{|c|c|c|c|c|c|}
\hline $\begin{array}{l}\text { Pierwszy } \\
\text { autorl } \\
\text { First } \\
\text { author }\end{array}$ & $\begin{array}{l}\text { Tytuł publikacji/ } \\
\text { Title of publication }\end{array}$ & $\begin{array}{l}\text { Liczba } \\
\text { cytowań/ } \\
\text { Number } \\
\text { of citations }\end{array}$ & $\begin{array}{l}\text { Czasopismo/ } \\
\text { Journal }\end{array}$ & $\begin{array}{l}\text { Impact } \\
\text { factor }\end{array}$ & $\begin{array}{l}\text { Dziedzina/ } \\
\text { Domain }\end{array}$ \\
\hline Veeramah V & $\begin{array}{l}\text { Utilization of re- } \\
\text { search findings by } \\
\text { graduate nurses } \\
\text { and midwives }\end{array}$ & 53 & $\begin{array}{l}\text { Journal of } \\
\text { Advanced } \\
\text { Nursing }\end{array}$ & 1,527 & NURSING \\
\hline Fullerton JT & $\begin{array}{l}\text { The International } \\
\text { Confederation of } \\
\text { Midwives' essen- } \\
\text { tial competencies } \\
\text { for midwifery } \\
\text { practice: examin- } \\
\text { ing the evidence }\end{array}$ & 15 & Midwifery & 1,116 & MIDWIFERY \\
\hline Fullerton JT & $\begin{array}{l}\text { The International } \\
\text { Confederation of } \\
\text { Midwives essen- } \\
\text { tial competencies } \\
\text { for basic midwi- } \\
\text { fery practice. an } \\
\text { update study: } \\
2009-2010\end{array}$ & 14 & Midwifery & 1,116 & MIDWIFERY \\
\hline $\begin{array}{l}\text { Bogdan- } \\
\text {-Lovis EA }\end{array}$ & $\begin{array}{l}\text { The contex- } \\
\text { tual influence } \\
\text { of professional } \\
\text { culture: Certified } \\
\text { nurse-midwives' } \\
\text { knowledge of } \\
\text { and reliance on } \\
\text { evidence-based } \\
\text { practice }\end{array}$ & 13 & $\begin{array}{l}\text { Social Sci- } \\
\text { ence and } \\
\text { Medicine }\end{array}$ & 2,733 & $\begin{array}{l}\text { HEALTH } \\
\text { CARE SCI- } \\
\text { ENCES }\end{array}$ \\
\hline Gijbels H & $\begin{array}{l}\text { A systematic } \\
\text { review evaluating } \\
\text { the impact of } \\
\text { post-registration } \\
\text { nursing and mi- } \\
\text { dwifery education } \\
\text { on practice }\end{array}$ & 9 & $\begin{array}{c}\text { Nurse } \\
\text { Education } \\
\text { in Practice }\end{array}$ & 0 & NURSING \\
\hline Kennedy H & $\begin{array}{l}\text { Science and mid- } \\
\text { wifery: Paradigms } \\
\text { and paradoxes }\end{array}$ & 8 & $\begin{array}{c}\text { Journal } \\
\text { of Mid- } \\
\text { wifery and } \\
\text { Women's } \\
\text { Health }\end{array}$ & 1,254 & MIDWIFERY \\
\hline
\end{tabular}

Źródło: opracowanie własne

Source: author's own analysis 


\section{Ograniczenia prezentowanej analizy piśmiennictwa}

Brak dostępu do pełnych darmowych tekstów ponad 25\% wszystkich odnalezionych pozycji był istotnym ograniczeniem i trudnością w przeprowadzeniu rzetelnej analizy piśmiennictwa naukowego.

\section{Podsumowanie}

Liczba pozycji w światowym piśmiennictwie naukowym poświęconym tematyce EBM oraz EBP jest zdecydowanie niewystarczająca, z kolei w dostępnym piśmiennictwie polskim nie odnaleziono żadnej pozycji dotyczącej stosowania praktyki zawodowej opartej na dowodach naukowych przez położne. Problematyka evidence-based practice poruszana jest przede wszystkim w kontekście podnoszenia jakości opieki nad pacjentem oraz wzrostu jej efektywności, głównie w pielęgniarstwie. W związku z niewystarczającą liczbą publikacji dotyczących evidence-based midwifery practice w naukach o zdrowiu należy propagować tę tematykę w polskim piśmiennictwie naukowym. Szczegółowa znajomość zasad evidence-based midwifery practice jest konieczna dla bezpiecznej, nowoczesnej i efektywnej praktyki zawodowej położnych i innych specjalistów nauk o zdrowiu, wpływa na podniesienie poziomu ich profesjonalizmu i umacnia ich pozycję zawodową w zespole terapeutycznym, jak również może wpłynąć pozytywnie na jakość współpracy z lekarzem.

\section{Piśmiennictwo}

1. Gajewski P, Jaeschke R, Brożek J. Podstawy EBM czyli medycyny opartej na danych naukowych dla lekarzy i studentów medycyny. Kraków: Medycyna Praktyczna. 2008.

2. Guyatt G. Praktyczne aspekty EBM. Med Prakt. 2003; 3: 37-38.

3. Haynes B. EBM - Jak uniknąć zalewu informacji? Med Prakt. 2003; 3: 41-43.

4. Glasziou P. EBM - Rola Cochrane Collaboration i Cochrane Library. Med Prakt. 2003; 3: 44-45.

5. Majkowski J. Medycyna oparta na dowodach - zalety i ograniczenia w praktyce klinicznej. Epileptologia. 2008; 16: 217-225.

6. Gajewski P, Jaeschke R, Mrukowicz J. Evidence based medicine (EBM) współczesną sztuką lekarską. Cele Polskiego Instytutu Evidence Based Medicine. Med Prakt. 2003; 3: 31-34.

7. Jaeschke R. Ocena technologii medycznych dla ich finansowania ze środków publicznych zgodna z zasadami EBM. Propozycja polskich rozwiązań. Med Prakt. 2004; 10, http:// www.mp.pl/artykuly/25153 (data dostępu: 9.02.2014).

8. Jaeschke R, Cook D, Guyatt G. EBM po Y2K. Med Prakt. 2000; 1, http://www.mp.pl/artykuly/10548 (data dostępu: 9.02.2014).

9. Greenhalgh T. How to Read a Paper: The Basics of Evidence Based Medicine. Wyd. II. London: BMJ Books; 2001.

10. Jaeschke R, Guyatt G, Cook D. Evidence based medicine (EBM), czyli praktyka medyczna oparta na wiarygodnych i aktualnych publikacjach. Med Prakt. 2000; 1-2: 120-124.
11. Gijbels H, O'Connell R, O'Connor D. A systematic review evaluating the impact of post-registration nursing and midwifery education on practice. Nurse Educ Pract. 2010; 10 (2): 64-69.

12. Fullerton JT, Thompson JB, Severino R. The International Confederation of Midwives essential competencies for basic midwifery practice. An update study: 2009-2010. Midwifery. 2011; 27 (4): 399-408.

13. Wickham S. Midwifery basics: understanding research (8). Critiquing research. Pract Midwife. 2010; 13 (7): 42-45.

14. Devane D, McCarthy B. Midwifery basics: understanding research (7). Understanding statistics in research papers. Pract Midwife. 2010; 13 (6): 40-42.

15. Hall J. Midwifery basics: understanding research (5). Interpreting qualitative data. Pract Midwife. 2010; 13 (3): 32-35.

16. Brennan M, Van Der Putten D. Midwifery basics: understanding research (4). Data collection methods and measurement. Pract Midwife. 2010; 13 (2): 34-39.

17. Casey D, Devane D. Midwifery basics: understanding research (3). Sampling. Pract Midwife. 2010; 13 (1): 40-43.

18. Devane D, Cooney A. Midwifery basics: understanding research (2). Research problems, purposes, questions and hypotheses. Pract Midwife. 2009; 12 (11): 34-37.

19. Wickham S. Midwifery basics: understanding research (1). Sources of evidence and research. Pract Midwife. 2009; 12 (9): $38-41$.

20. Farrar D, Syson J, Germaine T, Airey R. Research midwives: look at the evidence! Pract Midwife. 2011; 14 (7): 28-32.

21. Hunter B. Implementing research evidence into practice: some reflections on the challenges. Evid Based Midwifery. 11 (3): 76-80.

22. Bogdan-Lovis EA, Sousa A. The contextual influence of professional culture: Certified nurse-midwives' knowledge of and reliance on evidence-based practice. Soc Sci Med. 2006; 62 (11): 2681-2693.

23. Barroso R. Toward Unification of the Midwifery Profession: Looking Back to Guide Us Now. J Midwifery Womens Health. 2010; 55 (1): 2-4.

24. Fullerton J, Thompson J. The International Confederation of Midwives' essential competencies for midwifery practice: examining the evidence. Midwifery. 21: 2005; 2-13.

25. Humphreys A, Johnson S, Richardson J, Stenhouse E, Watkins M. A systematic review and meta-analysis: evaluating the effectiveness of nurse, midwife/allied health professional consultants. J Clin Nurs. 2007; 16: 1792-1808.

26. Rees C. Introduction to Research for Midwives. Wyd. II. Edynburg: Books for Midwives; 1997.

27. Sakala C. Current resources for evidence-based practice. J Midwifery Womens Health. 2005; 50 (4): 354-356.

28. Bluff R. Evaluating qualitative research. Brit $\mathrm{J}$ Midwifery. 1997; 5 (4): 232-235.

29. Johnson PG, Oshio S, Fisher MC, Fullerton JT. The 19992000 ACC task analysis of nurse-midwifery/midwifery practice: a consideration of the concept of professional issues. J Midwifery Womens Health. 2001; 46 (5): 313-320.

30. Albers L. "Evidence" and midwifery practice. J Midwifery Womens Health. 2001; 46: 130-136.

31. Barger M. Evidence-based practice: New opportunities, new responsibilities. J Midwifery Womens Health. 2001; 46 : 352-353.

32. Carr C, Schott A. Differences in evidence-based care in midwifery practice and education. J Nurs Scholarship. 2002; 34: 153-158.

33. Carr K. Developing an evidence-based practice protocol: Implications for midwifery practice. J Midwifery Womens Health. 2000; 45: 544-551. 
34. Erickson-Owens D, Kennedy H. Fostering evidencebased care in clinical teaching. J Midwifery Womens Health. 2001; 46: 137-145.

35. Sakala C. Evidence-based practice. J Midwifery Womens Health. 2003; 48: 69-71.

36. Sakala C, Corry M. What is evidence-based health care? J Midwifery Womens Health. 2001; 46: 127-128.

37. Veeramah V. Utilization of research findings by graduate nurses and midwives. J Adv Nurs. 2004; 47: 183-191.

38. Wagner M. Pursuing the birth machine: The search for appropriate birth technology. Camperdown: Ace Graphics; 1994.

39. Rooks JP. Evidence-based practice and its application to childbirth care for low-risk women. J Midwifery Womens Health. 1999a; 48: 355-369.

40. Oshio S, Johnson P, Fullerton J. The 1999-2000 task analysis of American nurse-midwifery/midwifery practice. J Midwifery Womens Health. 2002; 47: 35-41.

41. Kennedy H, Lowe N. Science and midwifery: Paradigms and paradoxes. J Midwifery Womens Health. 2001; 46: 91-97.
Artykuł przyjęty do redakcji: 05.08.2015

Artykuł przyjęty do publikacji: 12.12.2015

Źródło finansowania: Praca nie jest finansowana z żadnego źródła. Konflikt interesów: Autorzy deklarują brak konfliktu interesów.

\section{Adres do korespondencji:}

Joanna Gotlib

ul. Żwirki i Wigury 61

02-091 Warszawa

tel.: 225720 490, fax: 225720 491, tel. kom.: +48 608108028 e-mail: joanna.gotlib@wum.edu.pl

Zakład Dydaktyki i Efektów Kształcenia

Warszawski Uniwersytet Medyczny 